\title{
Technetium pertechnetate uptake in parathyroid adenoma
}

Ali Sellem (iD, Wassim Elajmi (iD, Hatem Hammami (iD

Miliatry Hospital of Tunis, Montfleury, Tunis

[Received 16 I 2020; Accepted 20 VII 2020]

We report the case of a 37-year-old woman newly diagnosed primary hyperparathyroidism with hypercalcemia $16.1 \mathrm{mg} / \mathrm{dL}$ (Ref range 8.5-10.1) and an increased parathyroid hormone level $110 \mathrm{pg} / \mathrm{mL}$ (reference range 10.0-70.0). She was referred to our department for scintigraphic localization of a parathyroid adenoma. The Tc-99m scintigraphy (Fig. 1) revealed a normal thyroid uptake associated with one focal uptake below the left lobe of the thyroid. A Tc-99m sestamibi parathyroid scan (Fig. 2) was performed showing an accumulation of the tracer in the same localization of Tc-99m focal uptake. It was a dilemma: is it an eccentric thyroid tissue that fixes the two radiotracers or a parathyroid adenoma fixing the ${ }^{99 \mathrm{~m}} \mathrm{Tc}$. Since we do not have the iodine 123 we realized an image (Fig. 3) with a tracer dose of iodine 131 showing no uptake below the left lobe of thyroid which allowed us to conclude to a parathyroid adenoma. The patient subsequently underwent minimally invasive cervicotomy with the resection of this lesion which was histologically diagnosed as a parathyroid adenoma.

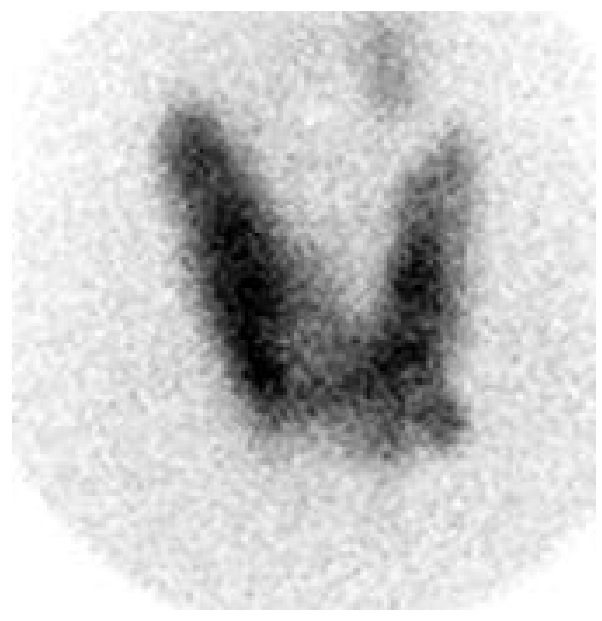

Figure 1. Tc-99m scintigraphy showing one focal uptake below the left lobe of thyroid

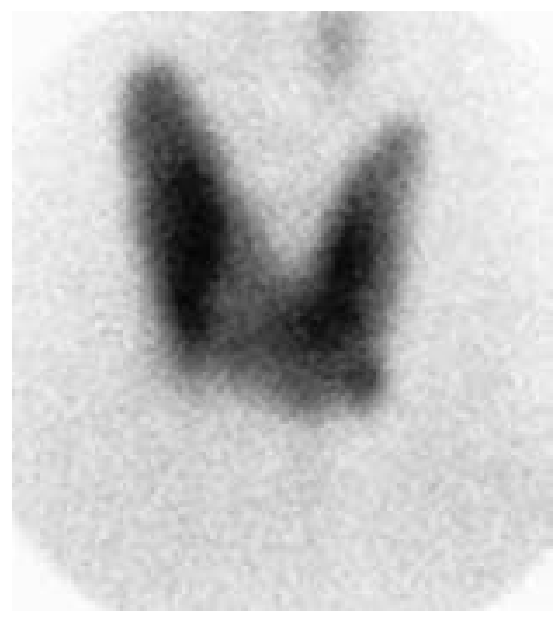

Figure 2. Sestamibi parathyroid scan showing an accumulation of the tracer in the same localization of Tc-99m focal uptake

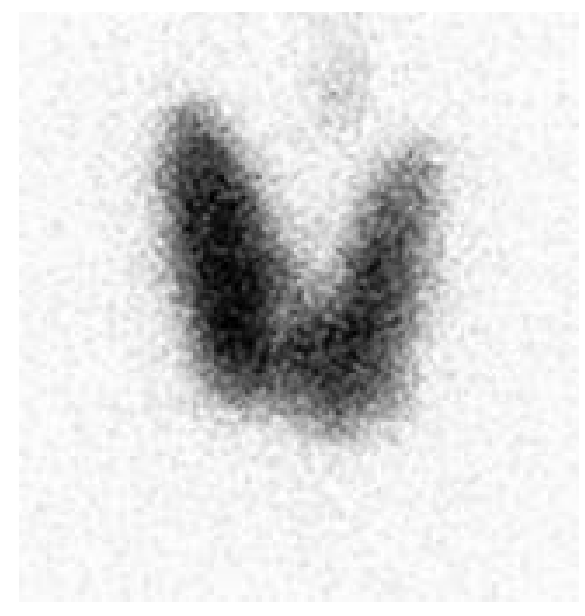

Figure 3. lodine 131scintigraphy showing no uptake below the left lobe of thyroid 